\title{
CHPP operational mode planning at electricity market conditions
}

\author{
Tatjana Petrova, PhD student, IEEE member \\ Renata Varfolomejeva, IEEE member \\ Institute of Power Engineering \\ Riga Technical University, RTU \\ Riga, Latvia
}

tatjana.petrova_1@,rtu.lv; renata_varfolomejeva@inbox.lv

\author{
Antans Sauhatas, IEEE member \\ Olegs Linkevics, IEEE member \\ Institute of Power Engineering \\ Riga Technical University, RTU \\ Riga, Latvia
}

sauhatas@eef.rtu.lv; olegs.linkevics@latvenergo.lv

\begin{abstract}
This article considers the operational modes development of CHPPs (combined and heat power plants) considering the influencing parameters as ambient temperature and heat demand. The optimization algorithm includes the operation of CHPP at market condition when the electricity market price changes hourly (as well as gas prices and emission charges are included). The proposal of CHPP submission to the electricity stock exchange is considered. According technical characteristics of real-life CHPP of Riga calculations and decision-making are made.
\end{abstract}

Keywords-combined heat and power plant; generation planning; power generation

\section{INTRODUCTION}

Lithuania and Latvia are operating in the Nord Pool Spot electricity market, but due to constraints in the transmission capacities between Baltic and Scandinavian countries, Latvian and Lithuanian bidding area is distinguished, thus electricity prices cannot be taken as exogenous when planning operational modes. That is why power plant regime planning in market condition plays an important role on decision making of electricity bids.

Nowadays, for implementing power plant mode planning tasks, specialized computer programs are widely used, the main task of which is optimal distribution of load among the generating sources. This article looks at the planning of the operational modes of CHPPs (combined and heat power plants) and the parameters influencing it as well as the operation of CHPPs at the electricity market as the bids are submitted to the Nord Pool Spot electricity market. A CHPP operational mode optimization program and its algorithm was described in the paper, which is based on the observance of CHPP equipment power limitations and characteristic curves, the climatic conditions (ambient temperature) as well as the forecast of the electricity market prices, $\mathrm{CO}_{2}$ emission and gas prices.

The specific regulation modes of CHPP are peculiar to each country especially in Northern countries and are topical issue in all over the world. CHHP operational management models has been tested and proposed in many articles [1-9]. The variety of articles are based on deterministic task statement to solve a problem of regime optimization for CHPP by minimizing the production costs. Namely, the cogeneration regime dispatch was discussed in articles. The review of done methods and algorithms for CHPP optimization is evaluated at the Figure 1. The ability of heat storage and its importance in household use is in top importance and should be considered.

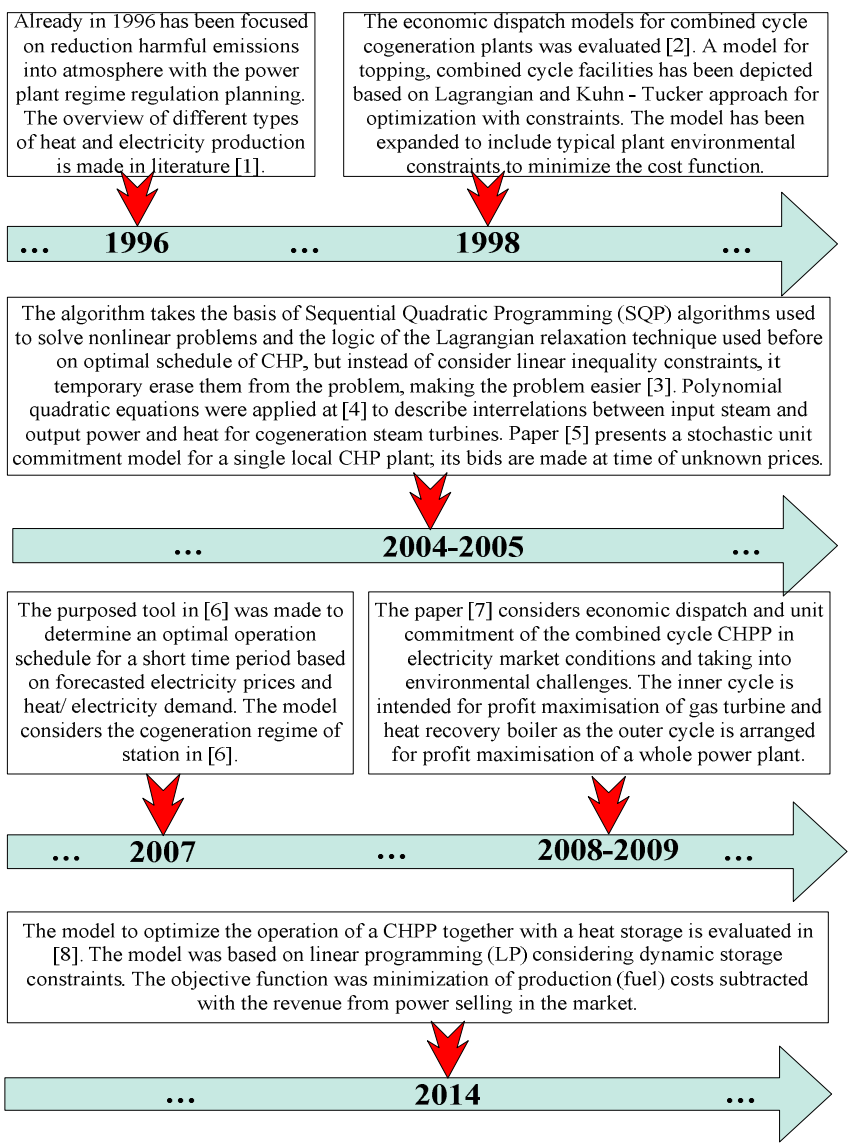

Fig. 1. The overview of developed methods and algorithms to solve the task of regime planning of CHPP

The optimization model in our paper considers:

1. The electricity market price schedule and its prognosis for 24 hour a day; 
2. The different CHPP working regime selection, such as: cogeneration regime; condensing and combined regime.

The contribution of the paper is based on heat and electricity power dispatch according market price schedule by maximizing the profit value and minimizing the harmful emissions generation into atmosphere in term of optimal working regime selection of CHPP.

The first part of the article analyses the principles of operation of the electricity market and the formation of prices on the market, the second part describes the principles of calculating and submitting bids to the market. The third part provides a description of the mathematical model, defining the target function and the limitations of the optimization task, developing a calculation algorithm and implementing the algorithm in the Visual Basic for Applications (VBA) programming language, by means of which a CHPP operational mode optimization program was set up in the Microsoft Office Excel environment. Section 4 contains an approbation of the developed mathematical model, calculating various CHPP operational modes and electricity market price scenarios; in the section 5 conclusions are provided. The developed optimization modes takes into account the electricity market price; heat price; $\mathrm{CO}_{2}$ quota price and gas price per each hour, as well should be mentioned that the algorithm of the model is selecting such regime type, which is more profitable in each hour, considering two CHPPs work in the electric power system.

\section{BIDDING TO THE ELECTRICITY MARKET AND PRICE FORMATION PRINCIPLES}

The prices of trade areas were introduced due to potentially different market situations in different trade regions and these prices reflect the distribution of electricity flows between trade regions, considering the possible cross-sections of power transmission lines.

As soon as all the market participants submitted their bids, all the buying and selling bids at every supply hour are summarized in two curves, the overall demand curve and the overall supply curve, which correspond to the electricity price as a function of the desirable amount of selling and buying at the hour under consideration. The price of trade regions is calculated on the basis of the available transmission power in the region. The difference between the prices in the trade regions is considerably influenced by bottlenecks in the transmission networks of power systems [10].

The market price of electricity at any day-ahead electricity market fluctuates within each trading day and may even change hourly. The considerable volatility of electricity prices at the day-ahead electricity exchanges is caused by a large number of factors that influence the formation of these prices. The market price of electricity depends both on changes in the demand and changes in the supply. Thus, the factors that influence the fluctuations of the electricity price can be tentatively divided into electricity demand side factors and supply side factors. Factors of the demand side: ambient temperature, natural lighting, day of the week, the economic situation in the country. Factors of the supply side: fuel prices, $\mathrm{CO}_{2}$ emission quota prices, availability of power plant generating capacities, import and export of electricity to third countries, availability of water resources accumulation and head point of hydropower plant reservoirs.

The prices at the electricity market are determined according to the so-called merit order at the crossing point of the supply and demand curves. The producers supply electricity from their power plants to the electricity market at a certain price. The decisive role in this price is played by the short-term marginal costs of power plants. The most expensive power plant covers the "top" of the demand and determines the price of electricity at the market at the moment. If the electricity consumption increases, for example, during morning and evening peak hours, then to meet the consumption, it is necessary to buy electricity from power plants with the highest marginal costs and therefore the market prices of electricity increase. Figure 2 shows the merit order curve of the trade regions of Latvia and Lithuania, the price determining and limiting role in this region belongs to the Riga CHPP as they are in the condition of availability.

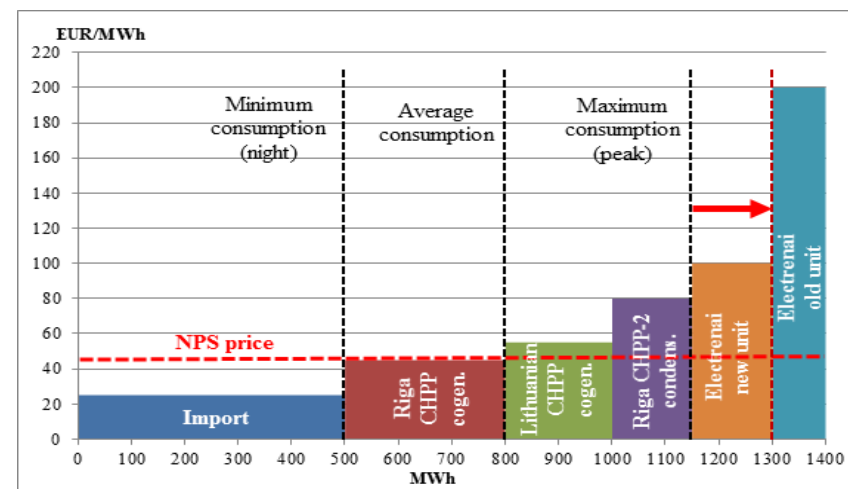

Fig. 2. Formation of market prices in Latvia and Lithuania on the basis of the merit order principle

On analyzing the curve, it can be concluded that the electricity prices at night, when a low electricity consumption is observed, assume the price level of the electricity imported from Estonia; at daytime, the Nord Pool Spot (NPS) market price in Latvia and Lithuania assumes the price level of the electricity produced in Latvia and Lithuania. In the case of higher consumption or in summer when there is insufficient heat load, the prices resemble the prices of the mixed and condensation mode of Riga CHPP-2. If no CHPPs were available in the region of Latvia and Lithuania, the prices would assume the price level of Elektrenai condensation power plant (Lithuania).

\section{DESCRIPTION OF THE MATHEMATICAL MODEL OF RIGA CHPP AND BIDDING TO THE MARKET}

The target of optimization within this study is the maximization of the total profit of Riga CHPP-1 and Riga CHPP-2 over a period of 24 trading intervals, which begins at 00:00 AM of the calendar day and ends at 12:00 PM of the calendar day. Within the optimization task, at each optimization step, or trading interval (a period with a duration of one hour, which begins at a full hour), an operational mode is to be set up at which all the generation equipment units are operated in an optimum way at the set market conditions. 
Within the given optimization task, the market conditions are understood to comprise the NPS market price at each production hour, the heat price according to the fixed tariff, the natural gas price and the $\mathrm{CO}_{2}$ quota price. The optimum dayand-night generation mode with the maximum profit is obtained as the sum of 24 optimization steps, determining the optimum mode with the maximum profit in each hour. The objective function is defined:

$$
\sum_{t=1}^{24} R_{\Sigma}^{t} \rightarrow \max
$$

where $\sum_{t=1}^{24} R_{\Sigma}^{t}-$ is the total profit of Riga CHPP-1

and Riga CHPP-2 over a 24-hour period, EUR.

The total profit of Riga CHPP-1 and Riga CHPP-2 is obtained by multiplying the produced electricity by its market price at the hour under consideration and the produced heat by the fixed heat price, subtracting from the sum the total variable production costs; thus, the target function can be expressed in developed form as follows:

$$
R_{\Sigma}^{t}=\left(P_{\Sigma}^{t} \cdot \Pi_{E}^{t}+Q_{\Sigma}^{t} \cdot \Pi_{Q}^{t}\right)-C_{\Sigma}^{t} \rightarrow \max
$$

The production costs of CHPP-1 and CHPP-2 are made from the natural gas and $\mathrm{CO}_{2}$ quota costs of both plants $[7,11]$ :

$$
C_{\Sigma}^{t}=C_{C H P P-1(\text { gas })}^{t}+C_{C H P P-1\left(\mathrm{CO}_{2}\right)}^{t}+C_{C H P P-2(\text { gas })}^{t}+C_{C H P P-2\left(\mathrm{CO}_{2}\right)}^{t},
$$

where $C_{C H P P-1(\text { gas })}^{t}$ - the gas costs of Riga CHPP-1, EUR;

$C_{C H P P\left(\mathrm{CO}_{2}\right)}^{t}$ - the $\mathrm{CO}_{2}$ costs of Riga CHPP-1, EUR;

$C_{C H P P(\text { gas })}^{t}$ - the gas costs of Riga CHPP-2, EUR;

$\mathrm{C}_{\mathrm{CHPP}-2\left(\mathrm{CO}_{2}\right)}^{t}$ - the $\mathrm{CO}_{2}$ costs of Riga CHPP-2, EUR.

The limitations of installed capacity and the generation range of the equipment of CHPP-1 and CHPP-2 are taken into account; those are described by the following inequalities [58]:

$$
\begin{gathered}
Q_{u n i t}^{\min } \leq Q_{\text {unit }} \leq Q_{\text {unit }}^{\max } \\
P_{\text {unit }}^{\min } \leq P_{\text {unit }} \leq P_{\text {unit }}^{\max } \\
Q_{H W B}^{\min } \leq Q_{H W B} \leq Q_{H W B}^{\max },
\end{gathered}
$$

where $Q_{\text {unit }}$ - the heat capacity of the CHPP's power unit, MW;

$P_{\text {unit }}$ - the electric capacity of the CHPP's power unit, MW;

$Q_{H W B}$ - the heat power of the hot-water boilers of the CHPP, MW.

The operation of Riga CHPP-1 can be described with the three chartered regimes: the CHPP's unit operating in the cogeneration mode (power and heat generation); with electricity and heat generation in the power unit in the cogeneration regime along with heat production in the hotwater boiler; and the last regime the heat generation by means of the hot water boiler and shutdown of the power unit. Depending on the heat load of the power unit of Riga CHPP-1, two or one gas turbines can be used in cogeneration mode alongside the steam turbine.
Unlike CHPP-1 where the electricity generation is made at cogeneration regime, the CHPP-2 can also operate in the condensation regime, generating electricity regardless of the heat load; also, it is possible to operate in a mixed mode, in which electricity is partly generated in cogeneration and partly at condensation modes. In common, CHPP-2 has five characteristic generation regimes: CHPP-2 cogeneration regime; condensation regime; mixed mode; generation of electricity and heat in the power units in co-generation mode and heat generation in the hot-water boiler; and, last, generation of heat only by means of the hot-water boiler.

Each iteration of the calculations consists in the determination of the optimum CHPP electricity and heat generation mode for one trading hour based on the maximum profit criterion, considering the limitations of the optimization task. As a result of the calculations, the optimum operational mode of Riga CHPP-1 and Riga CHPP-2 will be determined for the optimization period of 24 hours.

The empirical regularities and correlations, which were obtained on the basis of statistical data regarding the generation of heat and electricity and the consumption of natural gas in the period from 2013 till 2014 are used in the paper. In the developed algorithm of Riga CHPP are used the characteristic curves of the equipment of CHPP-1 and CHPP-2.

The dependence of the power units of CHPP-2 on the heat load can be approximated by the following second-order polynomial [9]:

$$
\alpha \cdot Q^{2}-\beta \cdot Q+\gamma
$$

where $\alpha, \beta, \gamma-$ known coefficients,

$Q-$ produced heat power, MW.

The following initial data for calculation are input into the first unit of the program: $\prod_{\mathrm{h}}$ - the heat price, $€ / \mathrm{MWh} ; \prod_{\mathrm{E}}$ the electricity price forecast at the Nord Pool Spot, $€ / M W h ; \mathrm{C}_{\mathrm{g}}$ - the natural gas end tariff, EUR/1000 $\mathrm{m}^{3} ; \mathrm{T}_{\text {ootdoor }}$ - the forecast outdoor temperature, ${ }^{\circ} \mathrm{C} ; \mathrm{C}_{\mathrm{CO} 2}$ - the price of the $\mathrm{CO}_{2}$ emission quotas on the previous working day, €/t; $\mathrm{Q}_{\mathrm{lhvMW}}-$ the actual lowest heating value of the natural gas fuel, $\mathrm{MWh} / 1000 \mathrm{~m}^{3}$.

The next step of the algorithm consists in the planning of the CHP generation mode, which starts by the distribution of the heat load between CHPP-1 and CHPP-2. This distribution is implemented by means of a random number generator: at each hour of trading, the forecast total heat load of CHPP-1 and CHPP-2 is distributed proportionally by means of a random number generator between CHPP-1 and CHPP-2. The heat load of CHPP-1 is obtained as a product of the total forecast heat load and a random number:

$$
Q_{C H P P-1}^{t=24}=Q_{\Sigma}^{t=24} \times R A N D O M_{1},
$$

Considering thereby the maximum installed heat capacity of CHPP-1; the heat load of CHPP-2 is obtained as the difference of the total forecast heat load and the heat load of CHPP-1, considering the limitation of the maximum installed heat capacity of CHPP-2:

$$
Q_{C H P P-2}^{t=24}=Q_{\Sigma}^{t=24}-Q_{C H P P-1}^{t=24} .
$$


After the total heat loads of CHPP-1 and CHPP-2 have been obtained, the electricity market price in the trading interval is compared to the CHPP's expenses for generating 1 MW in the CHP generation mode and the optimum heat loads of the CHPP power units are calculated considering the profit maximization criterion. In that case is made decision to use the heat load for electricity generation or it would be better to increase the heat load of the hot-water boiler by stopping the power units of the CHPP. After the heat load distribution between Riga CHPP-1 and Riga CHPP-2 was determined, considering all the limitations of the simulation task and the price forecast of the electricity market, the electric capacity for the CHP generation mode is determined, which is a function of the heat load of the power units and, consequently, a function of outdoor air temperature:

$$
P_{C H P P(\text { unit })}^{t}=f\left(T_{\text {outdoor }}, Q_{C H P P(\text { unit })}^{t}\right) .
$$

The total electrical load of the power plants at this step is determined as a sum of the electrical loads of CHPP-1, power unit-1 of CHPP-2 and power unit-2 of CHPP-2:

$$
P_{\Sigma}^{t}=P_{C H P P-1}^{t}+P_{C H P P 2.1}^{t}+P_{C H P P 2.2}^{t} .
$$

In order to determine the electrical load of the power plants, the characteristic curves of the CHPPs are used, which depict the dependence of the electrical load of the CHPPs on the heat load at various values of the heat load of the CHPPs. After the heat load and electric load of the power units of CHPP-1 and CHPP-2 have been determined, the total heat load of the hotwater boilers of the CHPPs and the optimum distribution of the heat load between the hot-water boilers are calculated. In order to implement the distribution of this heat load among the hotwater boilers, characteristic curves of hot-water boilers are used.

The next step consists of the calculation of the technical and economic parameters of the CHPP. Firstly, the CHPP gas consumption is calculated, which comprises the calculation of the CHPP total gas consumption, the consumption of natural gas for heat generation, and the consumption of natural gas for electricity generation. The above calculations are made on the basis of empirical formulas. For example, the total natural gas consumption of Riga CHPP-1 can be obtained, such as:

$$
G_{g}=f\left(Q_{H W B} ; \eta_{H W B} ; Q_{\text {unit }} ; P_{\text {cogen. }} ; \eta_{\text {cogen. }} ; Q_{l h v M W}\right),
$$

where $G_{g}$ - is the total consumption of natural gas, thousands of $\mathrm{m}^{3} / \mathrm{h}$; $Q_{H W B}$ - the heat load of the hot-water boilers, MW;

$\eta_{H W B}$ - the efficiency of the hot-water boilers;

$Q_{u n i t}$ - the heat load of the power unit, MW;

$P_{\text {cogen. }}$ - the electrical load in the cogeneration mode, MW;

$\eta_{\text {cogen. }}-$ the efficiency of the power unit in the cogeneration mode;

$Q_{l h v M W}$ - the lowest heating value of the natural gas fuel,

$\mathrm{MWh} /$ thousand of $\mathrm{m}^{3}$.

The same calculation is made for condensation mode. After determining the electricity price, the program compares this price with the market price of electricity in the corresponding trading interval. If the electricity price is less than the market price of electricity, it is decided to generate electricity in the condensing mode. Next, the CHPP's profit from the generation of electricity and heat in CHP generation and condensation mode is calculated, along with the total CHPP profit. At the conclusion of the iterations, we obtain a calculation of the profit and the profit of the present iteration is compared to the profit of the best iteration:

$$
R_{\Sigma}^{t, i}>R_{\Sigma}^{t, B E S T}
$$

If the profit of the present iteration is larger than the profit of the best iteration, then it is assumed as the best and the profit of the following iterations is compared to the profit of this iteration:

$$
R_{\Sigma}^{t, i}=R_{\Sigma}^{t, B E S T}
$$

After determining the profit of the best iteration, the iterations are concluded by determining the optimum CHPP generation plan. The developed generation plan of CHPP-1 and CHPP-2 is assumed as the optimum one and is output in the MS Excel software in the form of electronic tables.

\section{CALCULATIONS WITH THE CHPP MODEL}

In order to test the operation of the evaluated program of CHPP the various case studies are made. The statistical data, such as: ambient temperatures and Nord Pool Spot electricity market prices, need to be input in the program.

\section{A. An analysis of the sensitivity of the model towards the electricity prices and ambient temperature prognosis}

In order to analyze the sensitivity of the CHPP operational model towards electricity price changes, the data of the average heating season day with the 24-hour average ambient temperature $\mathrm{T}_{\text {outdoor }}=0,1{ }^{\circ} \mathrm{C}$ is input into program. The case study was tested for the NPS prices with the 24-hour average price - 57,93 EUR/MWh (the results are shown at the Figure $3)$. The program result in the bulk of the total heat load of the CHPPs being distributed to Riga CHPP-2 whereas Riga CHPP1 only meets a small share of the total heat load. In the graph, it can be seen that the power unit of Riga CHPP-1 operates with minimum loading until 5:00 AM when the electricity prices at the market are lower than the CHPP-1 CHP generation prices; the rest of the heat load of CHPP-1 is met by the hot water boiler. At 5:00 AM, the loading of the power unit increases as the electricity prices on the market increase and the hot water boilers are shut down until 10:00 PM when the electricity prices on the market again diminish. Upon analyzing the heat load distribution of CHPP-2, it can be seen that at 5:00 AM, the whole total heat load of CHPP-2 is met by the hot-water boilers but when the electricity prices on the market reach the CHPP-2 cogeneration prices, power unit-1 of CHPP-2 is started up, which operates till 10:00 PM with maximum loading. Power unit-2, in its turn, is started up at 6:00 AM, when the electricity prices on the market reach the CHPP-2 condensation prices, and operates till 10:00 PM. After the shutdown of both power units of CHPP-2, the total heat load of CHPP-2 is again met by the hot-water boilers. 


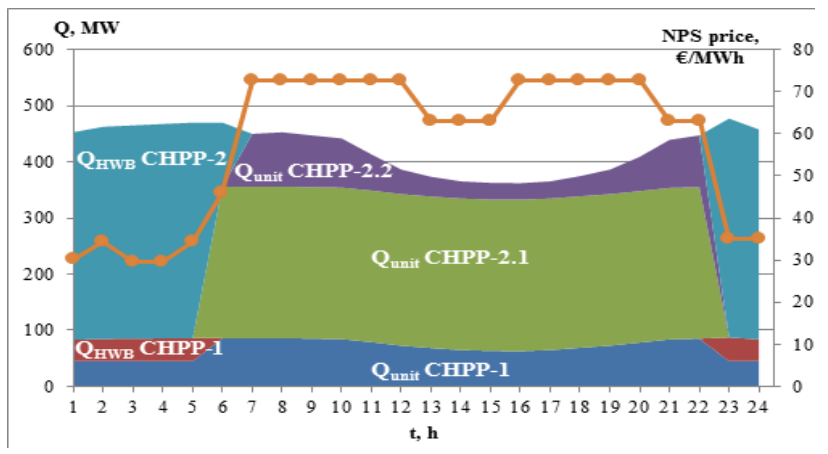

Fig. 3. The distribution of the heat load of the CHPP

Figure 4 shows the distribution of the electrical load of CHPP-1 and CHPP-2 in the given mode. The graph below shows that the calculations of the program have led to a decision to operate CHPP-1 based on heat load at daytime, starting from 5:00 AM, when the electricity prices on the market increase, and with minimum loading at night, starting from 10:00 PM, when the electricity price on the market is lower than the prices of the electricity generated at CHPP-1 in CHP generation mode.

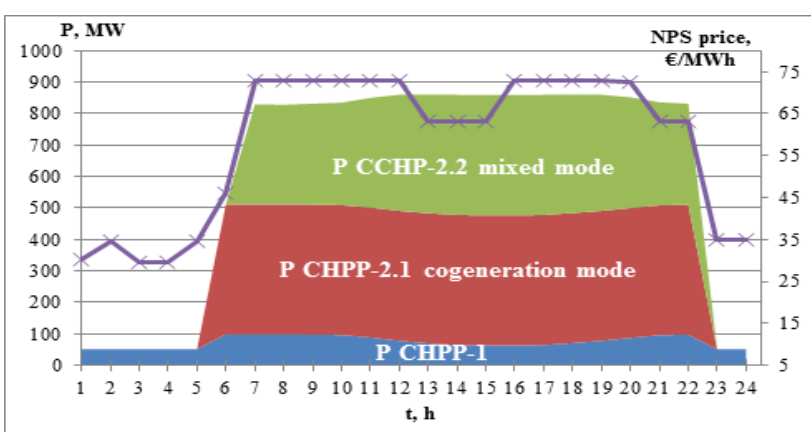

Fig. 4. The distribution of the CHPP electrical load

If we look at the electrical load distribution of CHPP-2 in the mode of this scenario, it can be seen that power unit-1 of CHPP-2 is started up at 5:00 AM, when the electricity price on the market reaches the CHPP-2 cogeneration prices, and operates cogeneration mode with a maximum capacity of 270 MW till 10:00 PM. Power unit-2, in its turn, is started when the electricity prices on the market reach the CHPP-2 condensation prices (at 6:00 AM), and operates till 10:00 PM, when the electricity prices on the market diminish to $35 \mathrm{EUR} / \mathrm{MWh}$.

\section{B. Comparison of the modelled CHPP mode with the real-life data}

The operational modes of the CHPPs in 2015 were taken as real-life data to compare the modelling results. The specimen day was January 13, 2015, when an average ambient temperature $\mathrm{T}_{\text {outdoor }}=3,9{ }^{\circ} \mathrm{C}$ was observed and the 24-hour average NPS price was 51.11 EUR/MWh. Figure 5 (a) shows the heat load distribution of the CHPP operational mode modelled by the program; Figure 5 (b) shows the heat load distribution of the actual CHPP mode at January 13, 2015.

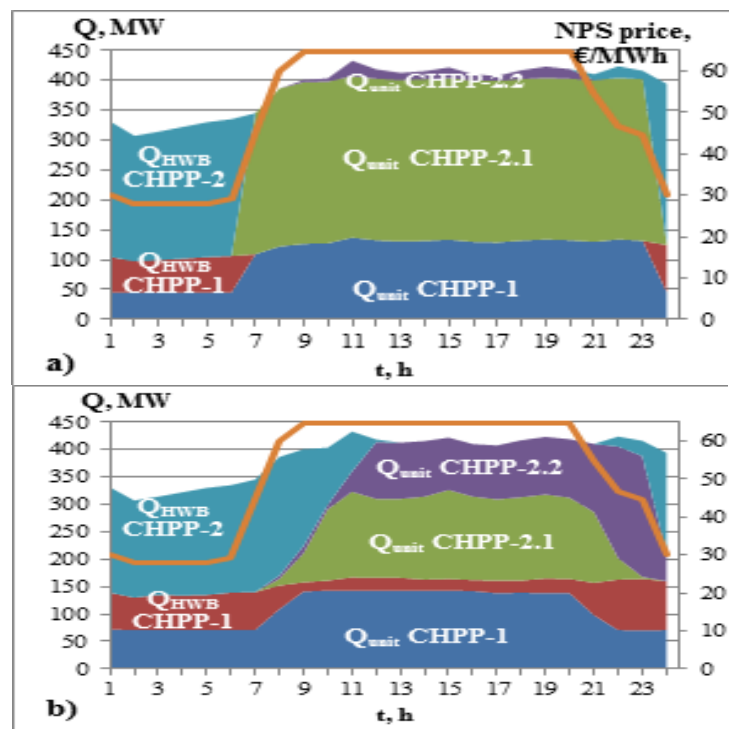

Fig. 5. The heat load distribution of the CHPP operational mode: a modelled; b - real-life data

According modelled CHPP operational mode the bulk of the heat generated by CHPP-1 is generated in the power unit, which, starting from 6:00 AM, when the electricity prices on the market reach the prices of electricity generated in cogeneration mode, takes over the whole heat load of CHPP-1 and operates at maximum capacity. The hot-water boilers of CHPP-1 are stopped from this moment until 11:00 PM since the heat load is not sufficient for their operation. Starting from 11:00 PM, the hot-water boilers are started up again and the heat load of the power unit is diminished to a minimum. Comparing the mode of CHPP-1 modelled by the program with the real-life mode of CHPP-1, it can be seen that in the case of the real-life mode the total heat load of CHPP-1 the total heat load of CHPP-1 is higher and therefore the hot-water boilers of CHPP-1 operate all through the day. In the real-life mode the heat load share of CHPP-1 is larger than in the modelled mode. The heat load of the CHPP-1 power unit was actually increased to the maximum load a hour later than it was done in the modelled mode. The real-life mode of CHPP-1 also differs from the modelled one in that actually the heat load in the CHPP-1 power unit was diminished to the technical minimum already at 9:00 AM, although the electricity price on the market exceeds the price of the electricity generated in cogeneration mode for two more hours and thus the heat load in the modelled mode diminishes from 11:00 PM.

The differences of the modelled CHPP operational mode and the real-life mode are to be explained by the fact that the program developed within this study considers and implements a CHPP operational mode model that functions without regard of the operational modes of the other power plants. However, in real-life conditions, this assumption cannot be applied since, as the operational modes of the power plants are optimized according to the profit maximization criterion, they need to be regarded as a united whole.

Figure 6 (a) shows the electrical load distribution in the CHPP operational mode modelled by the program and figure 6 (b) shows the electrical load distribution in the real-life CHPP operational mode on January 13, 2015. 


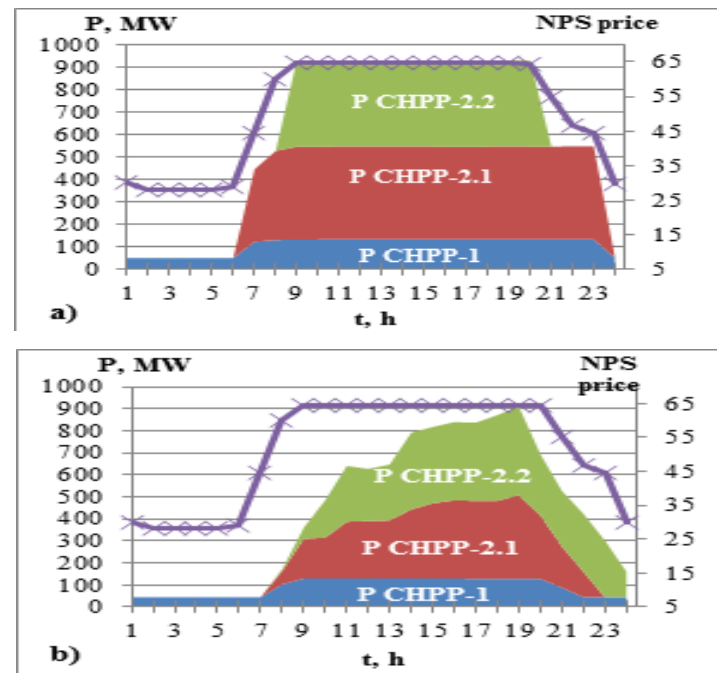

Fig. 6. The electrical load distribution of the modelled and real-life CHPP operational mode: $\mathrm{a}$ - modelled; $\mathrm{b}$ - real-life data

The CHPP-1 operates with the minimum load in both cases, which is equal to $45 \mathrm{MW}$, till 6:00 $\mathrm{AM}$ and 7:00 $\mathrm{AM}$, respectively. Then, as the electricity prices on the market reach the prices of the electricity generated in co-generation mode, power unit-1 of CHPP-2 is started up at 6:00 AM and operated in co-generation mode. After one hour, as the electricity prices on the market have reached the prices of the electricity generated at CHPP-2 in condensing mode, power unit-2 of CHPP-2 is started up at 7:00 AM and in the case of the mode modelled by the program, it is operated in a mixed mode with maximum loading until the electricity price on the market diminishes below the condensing mode prices at 9:00 PM. A similar situation is observed in the CHPP real-life mode: power units No. 1 and 2 are started up at 7:00 AM; power unit-1 operates in CHP generation mode according to the heat load and power unit-2 operates in mixed mode. In the real-life mode graph, it can be seen how the power units of CHPP-2 are started up and gradually take on the load. On the other hand, the simulated mode does not take account of the start-up peculiarities since the CHPP mode modelling program developed within this study assumes a number of simplifications and the peculiarities of CHPP start-up and shutdown are not taken into account in the program.

\section{CONCLUSIONS}

A program was developed for simulating the optimum operational modes of CHPPs, taking into account heat loads and electricity price changes, characteristic curves of equipment and capacity limitations by maximizing the profit. CHPP modes are strongly influenced by electricity prices at the Nord Pool Spot market. When the electricity price on the market is high, the developed program chooses to load the power units of the CHPPs whereas when low electricity prices set in, which usually happens at night, the program chooses to diminish the capacity of the power unit to the technical minimum (in the case of CHPP-1) or to completely shut down the power units (in the case of CHPP-2) and use the hot-water boilers for meeting the heat load.
The calculation algorithm of the developed program takes into account the cyclical operational modes of CHPPs considering the electricity market prices. In the calculation program, each iteration compares the electricity market prices with the prices of the electricity generated within the corresponding CHPP mode and a decision is made about the optimum loading of the CHPPs. The developed program considers and implements a CHPP operational mode model, which functions without regard to the operational modes of the other power plants. However, at real-life conditions, optimizing the operational modes of the power plants on the basis of the profit maximization criterion, these have to be regarded as a united whole.

\section{ACKNOWLEDGMENT}

\section{LATENERGI}

The work presented in this paper has been cofinanced by the National Research Program LATENERGI (2014-2017).

The development of this paper has been co-financed by the project nr.256/2012 'Power System Risks Management'

\section{REFERENCES}

[1] M. K. Mann, P. L. Spath, K. R. Craig. Economic and life cycle assessment of an integrated biomass gasification combined cycle system, 1996 IEEE pp. 2134-2139.

[2] R. M. Rifaat. Economic dispatch of combined cycle cogeneration plants with environmental constraints. 1998, Energy Management and Power Delivery, 1998. Proceedings of EMPD '98. 1998 International Conference on (Volume:1 ). P. 149 - 153 vol.1.

[3] M. A. Gonzalez Chapa, J. R. Vega Galaz. An Economic Dispatch Algorithm For Cogeneration Systems. 2004, Power Engineering Society General Meeting, 2004. IEEE. P. 989 - 994 Vol.1.

[4] A. Dolgicers, S. Guseva, A. Sauhats, O. Linkevics, A. Mahnitko, I. Zicmane. Market and Environmental Dispatch of Combined Cycle CHP Plant. 2009, IEEE Bucharest Power Tech Conference, June 28th - July 2nd, Bucharest, Romania. P. 1-4.

[5] H. F. Ravn, J. Riisom, C. Schaumburg-Müller. A Stochastic Unit Commitment Model for a Local CHP Plant. 2005, Power Tech, 2005 IEEE Russia, St. Petersburg. P. 1-5.

[6] D. Brujic, M. Ristic, K. Thoma. Optimal Operation of Distributed CHP Systems for Participation in Electricity Spot Markets. 2007, EUROCON 2007 The International Conference on "Computer as a Tool" Warsaw. P. 1463-1468.

[7] A. Dolgicers, O. Linkevics, A. Mahnitko, J. Gerhards, S. Guseva, I. Zicmane. Optimization of cogeneration power plants on the criteria of maximum profit. 2008, Elektroenergetika Journal Vol. 1 No. 2, December 2008. P. 33-37.

[8] E. Abdollahi, H. Wang, S. Rinne, R. Lahdelma. Optimization of energy production of a CHP plant with heat storage. 2014, IEEE Green Energy and Systems Conference (IGESC), Long Beach, CA. P. 30-33.

[9] O. Linkevics, A. Sauhats. Formulation of the Objective Function for Economic Dispatch Optimisation of Steam Cycle CHP Plants. 2005, Power Tech, 2005 IEEE Russia, St. Petersburg. P. 1-6.

[10] Nord Pool Spot. Available online: http://www.nordpoolspot.com/

[11] K. Sartora, S. Quoilina, P. Dewallefa. Biomass combined heat and power (CHP) plants connected to district heating (DH) networks. Preprint submitted to Elsevier, 2014. P. 1-21. 